\title{
Empowering Clinicians
}

\begin{abstract}
This chapter weaves together the various themes presented in earlier chapters: ethics and the self; informal versus formal ethical discourse; fast and slow thinking; the embeddedness of informal ethical discourse in the various interpretive communities of health care; the need to rely on, and use, informal ethical discourse in teaching health care ethics to trainees; and clinicians' need to rely on themselves and their colleagues in determining how to act ethically.
\end{abstract}

Keywords Health care - Clinical ethics - Implicit ethical framework Informal ethical discourse - The self - Interpretive community Morality of ordinary practice $\cdot$ Fast and slow thinking $\cdot$ Systems thinking

The central theme of this book is remarkably straightforward. Ethics starts with, and ends with, the self. Our informal ethical discourse, which emerges from our individual social experience and all it facets, is legitimate, powerful, and persuasive. It is the form of ethical discourse used by all but a tiny handful-perhaps several thousand, less than one in a million-of the earth's seven billion inhabitants. It is used daily, and exclusively, in business and in politics, as well as in private or personal interactions. It is our natural and first ethical language, and an effective and clear means of communication. It is sophisticated enough to address the most complicated problems that we face as individuals and groups

(C) The Author(s) 2018

S. Scher and K. Kozlowska, Rethinking Health Care Ethics, https://doi.org/10.1007/978-981-13-0830-7_11 
and citizens. And it is deeply embedded in our selves, in everything we do, and in every organization or group of which we are membersincluding all of our interpretive communities, both within and outside health care. As such, informal ethical discourse should be recognized and embraced as the proper language of clinical health care and of health care clinicians. The present book is, in effect, an elaboration of that simple theme.

For clinicians, the advantages of informal (versus formal) ethical discourse are many. First and foremost, it is our native language for ethics. We typically use it and apply it more or less automatically, as part of our fast thinking. We typically make judgments about our beliefs and actions, and about those of others, without any conscious process of reasoning. We immediately see most situations as fair or unfair, good or bad, mean-spirited or not; we respond to the world, in most cases, with straightforward ethical conclusions, and without even using explicitly ethical language. If asked, or when we find ourselves in a conflict or disagreement, or encounter a situation that puzzles us, we can make our reasoning explicit by engaging our slow thinking. But usually that's not necessary. To think that health professionals are somehow different, and that they need to think consciously and in terms of ethical principles or some other form of ethical theory, is to expect too much. For each of us, informal ethical discourse is a reflection of how we have come to think, over a lifetime, about the social world-including, for clinicians, health care-with all its complexities. In thinking (in informal ethical discourse) about the situations we encounter, we might judge that some situations violate rules ("he broke his promise") or principles ("what he did was really unfair"), that other situations have unacceptable consequences ("he just didn't realize that others would be hurt so badly"), and that still others reflect an absence of virtue, or good character ("if he had any sense of decency, he never could have done that"). These sorts of judgments come to us naturally, in the moment. And we slide seamlessly from one sort of judgment to another-from rules/ principles to consequences to virtues-just as naturally, though without seeing ourselves as applying principles or weighing consequences or judging actions on the presence or absence of virtues. We are, in a way, natural philosophers when it comes to ethics. Our informal ethical discourse can be rich and probing and every bit as good as anything any philosopher or bioethicist would present-and without invoking philosophy or bioethics. 
A philosopher or bioethicist might see this slide back and forth between rules/principles and consequences and virtues as a product of intellectual inconsistency, for these different frames of reference could be interpreted as reflecting three different theories from formal ethical discourse: principlism (or deontological ethics), consequentialism (or utilitarianism), and virtue ethics. ${ }^{1}$ For philosophers and bioethicists, each of these different approaches-considered as formal ethical theoriesexcludes the others. There is no way of balancing one theory, or one set of considerations, against any of the others. From the perspective of informal ethics, however, the inability to balance such considerations is a deficiency; we engage, and see a need to engage, in such balancing all the time. Situations are different; they call for different ways of thinking; and ethical wisdom is the capacity to understand when one approach, one set of considerations, is needed, or needs to be emphasized, rather than another. In the process, informal ethical discourse inescapably takes into account both social context and local knowledge (Geertz 2000), which is precisely what formal ethical discourse-with its commitment to unified, abstract, all-inclusive theories-finds difficult to do.

Given the above, efforts to teach formal ethical discourse to clinicians are arguably misdirected. There is no reason to think that clinicians, unless they set themselves on the lengthy, academic path (e.g., through graduate work in philosophy) of becoming experts in ethics, will ever master the field of formal ethics. And there's no reason that they should. Their informal ethics, supplemented when necessary by discussions with colleagues and even by the occasional referral to an ethics committee or ethics consultant, is adequate-better than adequate-for addressing the challenges of clinical practice. Informal ethics is something that clinicians not only understand but take with them wherever they go. From the institutional setting of the hospital, at one extreme, to the independence (and isolation) of clinicians who practice solo, at the other, informal ethics is always available as part of the self and as embedded in one's interpretive community. To displace it with formal ethics is to displace what's known and always available with something that's much less well understood and that's ultimately available only through experts.

It would be wrong to infer, however, that clinicians can and should simply sort things out as they see fit and that they should act by their own lights. Most notable in this context is each clinician's respective interpretive community itself. Empathy, respect for persons and their 
autonomy, attention to the interests and rights of patients and families, presumptive efforts to benefit patients and protect them from harm, cost efficiencies and savings, and all the other principles, values, and goals of bioethics are already embedded in the community's informal ethical discourse and in baseline rules for clinical management, in processes for dealing with patients and families, in the need to work collaboratively with other health professionals, and in methods of resolving conflicts when they arise. Responsible professional conduct requires attention to all of these matters, which are given central attention in health care training; they are not discretionary, though they are generally to be addressed in terms of informal, not formal, ethical discourse.

It may be helpful in this context to go back to what Stanley Fish saw as so central to interpretive communities. ${ }^{2}$ Each member is an "embedded practitioner whose standards of judgment, canons of evidence, or normative measures are extensions" of the community itself (Fish 1989, p. 144), with its institutional practices defined by established "distinctions, categories of understanding, and stipulations of relevance and irrelevance" (p. 141). An interpretive community, so defined, allows for disagreement and for freedom of action, but both are constrained and channeled by the goals, values, and standards of the community itself. In health care's various interpretive communities, these goals, values, and standards all orient themselves around the care of patients.

This informal ethical discourse embedded in health care's various interpretive communities provides a thread of continuity and commonality among all health professionals, and it also provides them with a common language in communicating with both patients and other health professionals. ${ }^{3}$ In any particular society, the particular variations of informal ethical discourse embedded within health care's various interpretive communities will necessarily be ones that grew out of the local, informal ethical discourse that trainees bring with them into their professional training and that they then proceed to build upon and expand through their professional training in particular fields and subsequent clinical careers. Over time, the local varieties of informal ethical discourse within the different fields of health care evolve in response to new knowledge and new challenges. In this context one obvious advantage of that discourse is its flexibility and adaptability-its capacity for interpretation and reinterpretation. Over time, new, highly nuanced rules or behaviors can emerge and become entrenched in the practices of an interpretive community. In health care, where baseline knowledge is always growing and 
modes of delivery are now evolving rapidly because of computerization and the Internet, this capacity for growth is especially important.

That said, informal ethical discourse is sometimes not enough. The problem at hand may resist closure or be so complex or novel that one doesn't know quite where to start, even after discussions with colleagues, senior or otherwise, and trusted friends. In such circumstances, the various dimensions of the bioethical presence in health care may prove to be valuable. Bioethicists (e.g., institutionally based consultants) may be able to bring new light to the situation by separating out and clarifying problems or interwoven threads. Ethics committees may do the same. Lawyers and administrators, whether institutionally based or otherwise available for consultation, may have the type of information that will simplify a problem or perhaps even determine the solution.

The tools of bioethics - in particular, the capacity to see problems from the more general perspective of ethical theory-are both a strength and a weakness, depending upon one's frame of reference. First, the strength. Informal ethics, unless pursued with considerable energy and intelligence, may sometimes fall short, especially in relation to what one might call the major "issues of the day," including genetic engineering, cloning, disputes over the possession and disposal of frozen embryos, and so on. In this context bioethicists, as well as philosophers and theologians, might well be seen as having a special capacity to advance public discussion and understanding. Such contributions are of fundamental importance to the life of a nation. That said, closure-no matter how intense the discussion or how rich the insight-is likely to remain elusive and will ultimately be decided by courts, legislatures, or some other sort of deliberative body (including, perhaps, a country's own electorate).

Second, the potential weakness. Looking at ethics expertise from the perspective of teaching health care trainees and, more broadly, informing and educating practicing clinicians, the value to health professionals of formal bioethical discourse is an open question. We have presented the view that each field of health care is a separate interpretive community with its own standards, goals, and values of various kinds. By the same token, each of these interpretive communities embodies, as it were, the informal ethical discourse of that very community. Ethical standards and values are embedded in the thoughts, emotions, and actions of the community's own members. Persons trained in philosophy or bioethics may or may not be able to work, as they must on this view of clinical ethics, from the "inside." Except in unusual 
situations, and certainly not day to day, formal ethical discourse does litthe to elaborate or illuminate the embedded standards, values, and goals of health care's various interpretive communities. If a philosopher or bioethicist can work using the Socratic method and translate his or her own knowledge into informal ethical discourse and into a form that is internal to the particular interpretive community-then that's good. If not, professional schools need to look elsewhere and perhaps train their own members to do that kind of work (perhaps even with the help of philosophers or bioethicists).

By the same token, the bioethics literature itself will not necessarily be helpful to clinicians. If clinicians are interested in particular ethical problems that have been addressed in the literature, reading articles or books or reports may prove valuable, or it may not. The judge of that is each individual clinician. If the articles or books prove helpful and serve to inform a clinician's informal ethical thinking, then that's all well and good. But if the material isn't helpful (e.g., because it is too abstract, couched in unfamiliar language, or not sufficiently connected to the clinician's concerns), then the clinician should just move on. On the approach presented in this book, the clinician and clinical practice - and more generally, the standards of the respective interpretive communities - are the parameters for judging relevance and usefulness. We are confident that clinicians can make those judgments themselves.

Through all of the above discussion-and, implicitly, throughout this book-the constant thread is that the formal ethical discourse of bioethicists and the informal ethical discourse of clinicians operate, from a systems perspective, on different levels of complexity (Bateson 2000; Capra 1997; Checkland 1981). For situations that resist consensus or that raise significant, complex issues of ethics or public policy, the formal tools of bioethical discourse may well prove useful. For a flexible, workable approach to the ethical challenges, small and large, of day-to-day clinical practice, informal ethical discourse is sufficient and, indeed, preferable (Scher and Kozlowska 2011). What has been, and remains, unfortunate is that one domain has come so much to dominate the other over the history of the bioethics movement, and that the informal ethical discourse of health care trainees and clinicians has come to be considered not good enough. We think it is time to restore the balance. 


\section{Notes}

1. The Stanford Encyclopedia of Philosophy's entry on virtue ethics (2016) provides a succinct comparison of these three theoretical approaches to ethics. Virtue ethics

may, initially, be identified as the [theoretical approach] that emphasizes the virtues, or moral character, in contrast to the approach that emphasizes duties or rules (deontology) or that emphasizes the consequences of actions (consequentialism). Suppose it is obvious that someone in need should be helped. A utilitarian will point to the fact that the consequences of doing so will maximize well-being, a deontologist to the fact that, in doing so the agent will be acting in accordance with a moral rule such as "Do unto others as you would be done by" and a virtue ethicist to the fact that helping the person would be charitable or benevolent.

2. For more on Fish and interpretive communities, see Chapter 7.

3. As Merrilyn Walton and Ian Kerridge note in "Do No Harm: Is It Time to Rethink the Hippocratic Oath?" (2014, p. 20), effective communication in today's world of health care is itself a patient-safety issue:

For a patient to benefit from his or her health care, health professionals must be both technically competent and able to effectively communicate with their patient, the patient's carers and with one another. This idea that a patient's care relates to the capacity of other health practitioners to communicate efficiently, accurately and in a timely manner in all their communications is central to understanding health care as a system.

\section{REFERENCES}

Bateson, G. (2000). Steps to an ecology of mind. Chicago: University of Chicago Press.

Capra, F. (1997). The web of life: A new synthesis of mind and matter. London: Flamingo.

Checkland, P. (1981). Systems thinking, systems practice. Chichester, England: Wiley.

Fish, S. E. (1989). Doing what comes naturally: Change, rhetoric, and the practice of theory in literary and legal studies. Durham, NC: Duke University Press.

Geertz, C. (2000). Local knowledge: Further essays in interpretive anthropology (3rd ed.). New York: Basic Books.

Hursthouse, R., \& Pettigrove, G. (2016). Virtue ethics. In E. N. Zalta (Ed.), Stanford encyclopedia of philosophy. https://plato.stanford.edu/entries/ ethics-virtue/. 
Scher, S., \& Kozlowska, K. (2011). The clinician's voice and the limits of bioethics. Australian and New Zealand Journal of Family Therapy, 32(1), 15-32.

Walton, M., \& Kerridge, I. (2014). Do no harm: Is it time to rethink the Hippocratic Oath? Medical Education, 48(1), 17-27.

Open Access This chapter is licensed under the terms of the Creative Commons Attribution-NonCommercial-NoDerivatives 4.0 International License (http:// creativecommons.org/licenses/by-nc-nd/4.0/), which permits any noncommercial use, sharing, distribution and reproduction in any medium or format, as long as you give appropriate credit to the original author(s) and the source, provide a link to the Creative Commons license and indicate if you modified the licensed material. You do not have permission under this license to share adapted material derived from this chapter or parts of it.

The images or other third party material in this chapter are included in the chapter's Creative Commons license, unless indicated otherwise in a credit line to the material. If material is not included in the chapter's Creative Commons license and your intended use is not permitted by statutory regulation or exceeds the permitted use, you will need to obtain permission directly from the copyright holder.

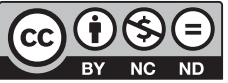

